\title{
CARACTERIZAÇÃO TECNOLÓGICA DOS QUARTZO SIENITOS COM HIPERSTÊNIO BUTTERFLY BEIGE E BUTTERFLY GREEN.
}

\section{TECHNOLOGICAL CHARACTERIZATION OF BUTTERFLY BEIGE AND BUTTERFLY GREEN QUARTZ SYENITES WITH HYPERSTHENE.}

\author{
Thiago Motta BOLONINI ${ }^{1}$, Antonio Misson GODOY ${ }^{2}$ \\ (1) Programa de Pós-graduação em Geologia Regional, Instituto de Geociências e Ciências Exatas, Universidade Estadual Paulista, \\ UNESP. Rio Claro, São Paulo, Brasil. Endereço Eletrônico:_thiagotro@gmail.com. \\ (2) Departamento de petrologia e Metalogenia, Instituto de Geociências e Ciências Exatas, Universidade Estadual Paulista, UNESP.
} Rio Claro, São Paulo, Brasil. Endereço Eletrônico: mgodoy@rc.unesp.br

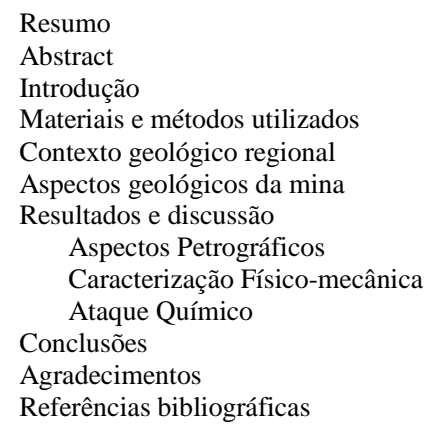

RESUMO - As rochas ornamentais estudadas são quartzo sienitos com hiperstênio conhecidos comercialmente como Butterfly Beige e Butterfly Green, extraídas em Barra de São Francisco-ES. O estudo visa, a partir da realização da caracterização tecnológica, auxiliar na orientação das possíveis utilizações destes litotipos que apresentam grande similaridade petrográfica. Os resultados de ensaios, no geral, encontram-se dentro dos padrões para rochas graníticas, com exceção do desgaste Amsler (Butterfly Beige 2,19 mm; Butterfly Green 1,87 mm) e do módulo de ruptura (Butterfly Green seco 8,03 MPa e 7,64 MPa após congelamento e degelo; Butterfly Beige seco 4,07 MPa e 4,56 MPa após congelamento e degelo), indicando a necessidade de cautela para utilização em ambientes de alto tráfego e em fachadas. Em contrapartida, apresentam valores de porosidade (Butterfly Beige 0,61\%; Butterfly Green 0,52 \%) e absorção d'água (Butterfly Beige 0,23\%; Butterfly Green 0,19\%) que refletem segurança às suas aplicações em ambientes úmidos. Com relação ao ataque químico, é importante verificar a composição química do agente de limpeza a ser utilizado para manutenção sendo aconselhado, na dúvida, utilizar apenas um pano umedecido para realizar a limpeza uma vez que o ácido clorídrico gera alterações cromáticas severas (Butterfly Green) e que o ácido cítrico provocou a maior perda de brilho em ambas as rochas.

Palavras-chave: geologia, caracterização tecnológica, rochas ornamentais.

\begin{abstract}
The dimension stones studied are quartz syenites with hypersthene commercially known as Butterfly Beige and Butterfly Green, extracted in Barra de São Francisco-ES. The aim of this study, from the realization of technological characterization, is to help in the orientation of the possible uses of these lithotypes that present great petrographic similarity. The test results are generally within the standards for granite rocks, with the exception of Amsler wear (Butterfly Beige $2.19 \mathrm{~mm}$, Butterfly Green 1.87 $\mathrm{mm}$ ) and rupture modulus (dry Butterfly Green $8.03 \mathrm{MPa}$ and $7.64 \mathrm{MPa}$ after freezing and thawing; dry Butterfly Beige 4.07 MPa and 4.56 MPa after freezing and thawing), indicating the need for caution for use in high traffic and facade environments. On the other hand, they have values of porosity (Butterfly Beige 0.61\%; Butterfly Green 0.52\%) and water absorption (Butterfly Beige 0.23\%; Butterfly Green $0.19 \%$ ) that reflect safety to their applications in humid environments. In relation to the chemical attack, it is important to check the chemical composition of the cleaning agent to be used for maintenance and it is advisable to use only a moist cloth to clean it since the hydrochloric acid causes severe chromatic changes (Butterfly Green) and that citric acid caused the greatest loss of brightness in both rocks.
\end{abstract}

Keywords: geology, technological characterization, dimension stones.

\section{INTRODUÇÃO}

O Estado do Espírito Santo contribuiu, no período de janeiro a agosto de 2016, com $92,85 \%$ dos US\$ 633.135.468 gerados pelas exportações nacionais de chapas de rochas ornamentais silicáticas. Uma boa parte desses materiais $(14,78 \%$ das chapas; US\$ 81.964.521,00) é beneficiada no município de Barra de São Francisco (CENTROROCHAS, 2016).

As rochas objetos deste estudo estão inseridas neste contexto onde, após a extração, passam pelo processo de corte dos blocos em chapas e pelo polimento que impõem solicitações hidráulicas, térmicas e mecânicas às rochas que, por sua vez, respondem a elas de formas diferentes definindo a qualidade das superfícies acabadas. Entretanto, mesmo depois de instaladas, as superfícies podem sofrer alterações por serem submetidas a diversas solicitações como a abrasão (tráfego intenso de pessoas), os esforços flexores (ação dos ventos: aplicação em fachadas altas com sistema de 
ancoragem por inserts metálicos), esforços compressivos (fundações e calçamentos), além das solicitações físico-químicas provocadas pela ação do intemperismo (ação da água e cristalização de sais), das interações com outros materiais utilizados na construção civil (reação álcali-agregado), das interações com produtos de limpeza (sabões, desinfetantes, removedores de manchas) e com ácidos oriundos de produtos alimentícios (vinagres e ácidos presentes em frutas).

Em função destas solicitações, testes de caracterização precisam ser realizados para avaliar a capacidade que as rochas possuem de suportá-las.

Além disso a mudança de coloração (de verde para amarelada) da variedade comercialmente conhecida como Butterfly Green, quando assentadas em ambientes externos, motivou a realização deste trabalho, pois mesmo com o devido tratamento dado à sua superfície durante o acabamento na indústria (proteção por resinagem).

Diversas publicações tratam do tema caracterização tecnológica de rochas ornamentais como ferramenta auxiliar à escolha de materiais para as diversas aplicações na construção civil como Aires-Barros et al. (1991), Vidal et al. (1999), Frazão \& Frajallat (1995, 1996), Frascá (2002), Frazão (2002), Pazzeto (2011), Bolonini
(2011, 2015), Saar $(2013,2015)$ e Bolonini et al. (2013, 2016a, 2016b, 2016c).

Este estudo apresenta a caracterização dos aspectos tecnológicos de dois exemplares de quartzo sienitos com hiperstênio comercialmente denominados de Butterfly Green e Butterfly Beige utilizados como rochas para revestimento e que são extraídos em um mesmo corpo intrusivo no município de Barra de São Francisco, Estado do Espírito Santo. Apesar de apresentarem grande similaridade composicional, foram selecionadas por exibirem cores muito distintas. O Butterfly Green, que ocorre em maior quantidade na pedreira, possui cor verde atribuída (CPRM, 2007b) à presença de inclusões fluidas de $\mathrm{CO}_{2}$.

$\mathrm{O}$ estudo visa propiciar informações técnicas para orientar as possíveis utilizações das rochas testadas frente às diversas situações de solicitação às quais podem ser submetidas quando aplicadas como revestimento ou como simples peças de ornamentação.

A partir desta concepção espera-se agregar ao conhecimento geológico do maciço rochoso os parâmetros técnicos obtidos, possibilitando um melhor aproveitamento deste bem mineral com o fornecimento de uma sólida base de informações técnicas que servirão de guias para especialistas em diversas utilizações na construção civil.

\section{MATERIAIS E MÉTODOS UTILIZADOS}

As rochas ornamentais Butterfly Beige e Butterfly Green estudadas são duas variedades de quartzo sienitos com hiperstênio (Figuras 1A, 1B) extraídas no município de Barra de São Francisco, no distrito de Itaperuna, região noroeste do Estado do Espírito Santo. São rochas com texturas inequigranulares, hipidiomórficas, de granulações grossas a porfiríticas variando de $0,2 \mathrm{~cm}$ a $4,5 \mathrm{~cm}$, estrutura isotrópica, compostas basicamente por microclínio, plagioclásio (oligoclásio), quartzo, granada, biotita e hiperstênio.

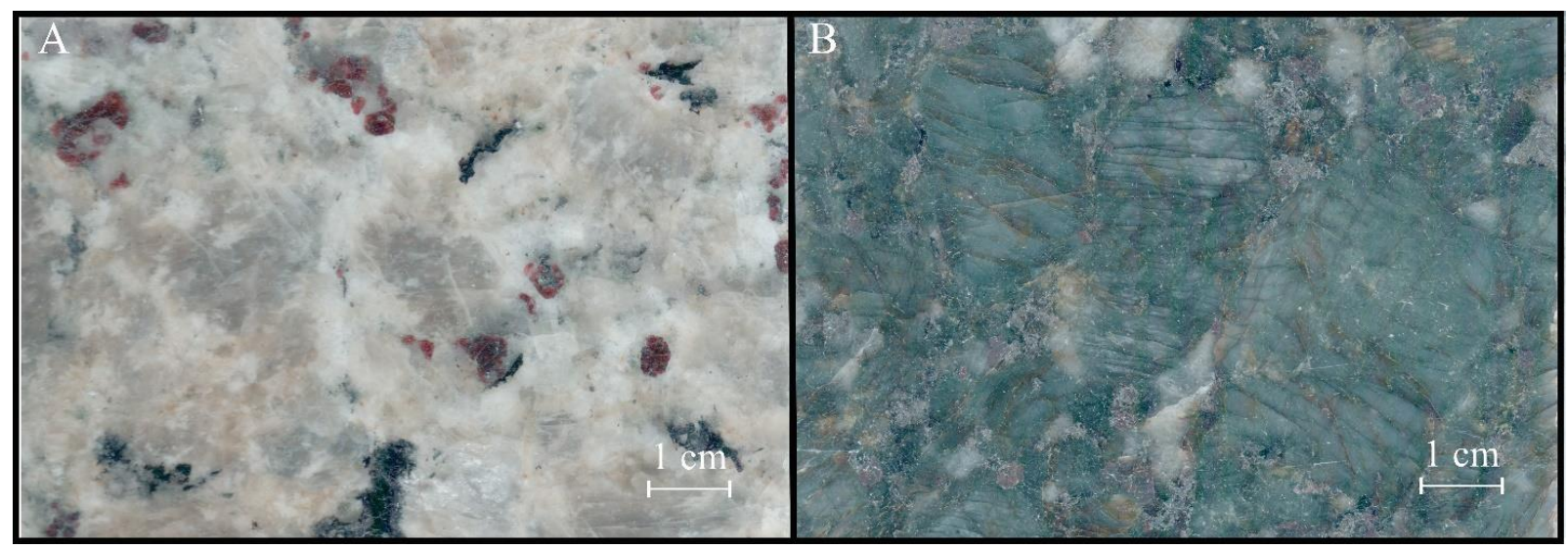

Figura 1 - Ilustração das rochas ornamentais granada - quartzo sienitos com hiperstênio caracterizadas neste trabalho. Legenda: A) Butterfly Beige; B) Butterfly Green. 
Para caracterizar tecnologicamente os materiais supracitados foram utilizados os ensaios e as análises, realizados no Laboratório de Rochas Ornamentais do Departamento de Petrologia e Metalogenia - LABRO do Instituto de Geociências e Ciências Exatas Universidade Estadual Paulista UNESP, a saber:

- Análise petrográfica: realizada conforme orienta a norma ABNT NBR 15.845 - anexo A (ABNT, 2010a);

- Determinações da densidade aparente, porosidade aparente e absorção de água, conforme orienta a norma ABNT NBR 15.845 - anexo B (ABNT, 2010b);

- Determinação da resistência ao desgaste abrasivo Amsler, conforme orienta a norma
ABNT NBR 12.042 (ABNT, 1992);

- Determinação da resistência à compressão uniaxial, conforme orienta a norma ABNT NBR 15.845 - anexos D e E (ABNT, 2010c; ABNT, 2010d) nas condições seca, saturada e após os ciclos aplicados de congelamento e degelo;

- Determinação da resistência à flexão em três pontos, conforme orienta a norma ABNT NBR 15.845 - anexos D e F (ABNT, 2010c; ABNT, 2010, e), nas condições seca, saturada e após os ciclos de congelamento e degelo;

- Determinação da resistência ao ataque químico com base na norma ABNT NBR 13.818 - anexo H (ABNT, 1997), utilizando os reagentes e os tempos de exposição dispostos na tabela 1 .

Tabela 1 - Relação de reagentes e tempos de exposição durante o ensaio de ataque químico.

\begin{tabular}{|c|c|}
\hline Reagentes e concentrações & Tempos \\
\hline Hidróxido de potássio $(\mathrm{KOH} 30 \mathrm{~g} / \mathrm{L})$ & $96 \mathrm{~h}$ \\
\hline Hidróxido de potássio (KOH 100g/L) & $96 \mathrm{~h}$ \\
\hline Ácido Clorídrico (HCl 3\%vv) & $96 \mathrm{~h}$ \\
\hline Ácido Clorídrico (HCl 18\%vv) & $96 \mathrm{~h}$ \\
\hline Cloreto de Amônia $\left(\mathrm{NH}_{4} \mathrm{Cl} 100 \mathrm{~g} / \mathrm{L}\right)$ & $24 \mathrm{~h}$ \\
\hline Ácido Cítrico $\left(\mathrm{C}_{6} \mathrm{H}_{8} \mathrm{O}_{7} 100 \mathrm{~g} / \mathrm{L}\right)$ & $24 \mathrm{~h}$ \\
\hline Ácido Lático $\left(\mathrm{C}_{3} \mathrm{H}_{6} \mathrm{O}_{3} 5 \% \mathrm{vv}\right)$ & $24 \mathrm{~h}$ \\
\hline Hipoclorito de Sódio (NaClO 20mg/L) & $24 \mathrm{~h}$ \\
\hline
\end{tabular}

As superfícies dos corpos de prova destinadas ao ensaio foram digitalizadas, antes e após o mesmo, para efeito de comparação, com o uso de um scanner de mesa.

Tubos de PVC com diâmetro de $8 \mathrm{~cm}$ foram colados na superfície dos corpos de prova e cobertos com placas de petri para evitar evaporação em excesso das substâncias utilizadas.

Antes e após o ensaio de ataque químico, foram feitas 3 medições de brilho, para cada corpo de prova, com o uso de um Glossmeter micro-Tri-Gloss (com a geometria de $85^{\circ}$ ).
Os resultados para este ensaio são apresentados em função da porcentagem da perda de brilho calculada através da equação 1 :

$$
\left(\frac{B i-B f}{B i}\right) \times 100
$$

Onde: $\boldsymbol{B i}=$ Brilho Inicial $\boldsymbol{e} \boldsymbol{B} \boldsymbol{f}=$ Brilho final.

A avaliação e discussão dos resultados foram realizadas, principalmente, com base nas propriedades petrográficas dos litotipos e suas variações após os testes e na norma ABNT NBR 15.844 (ABNT, 2010f).

\section{CONTEXTO GEOLÓGICO REGIONAL}

As rochas estudadas são extraídas em um maciço que aflora sob a forma de um corpo intrusivo alongado com aproximadamente $35 \mathrm{~km}$ de eixo maior de direção NE-SW. Este corpo intrusivo está inserido no contexto da porção sudeste do Orógeno Araçuaí (Pedrosa-Soares et al., 1992, 2001, 2006, 2007; Martins et al., 2004; Marshak et al., 2006; Alkmin et al., 2007; Noce et al., 2007).
Na região da Folha de Mantena-MG (CPRM, 2007a), as unidades magmáticas e metamórficas relacionadas ao Orógeno Araçuaí correspondem, respectivamente, às Supersuítes G5 (Cambriano) e G2 (Neoproterozoico) (Pedrosa-Soares et al., 2006). Os autores, em 2007, classificam as Supersuítes como Suíte G5 (Cambriano), na qual o corpo intrusivo de onde são extraídas as rochas utilizadas neste estudo está inserido, e Suíte G2 
(Neoproterozoico), como mostra a figura 2.

Roncato Junior (2009), entretanto, coloca o Orógeno Araçuaí subdivido, na região da folha geológica de Mantena-MG, entre a Cambriana Suíte Intrusiva Aimorés (Charnockito) e a
Neoproterozoica Suíte Carlos Chagas (deformada, composta basicamente por granadabiotita gnaisses com sillimanita).

Tais subdivisões classificam de forma particular as mesmas rochas.

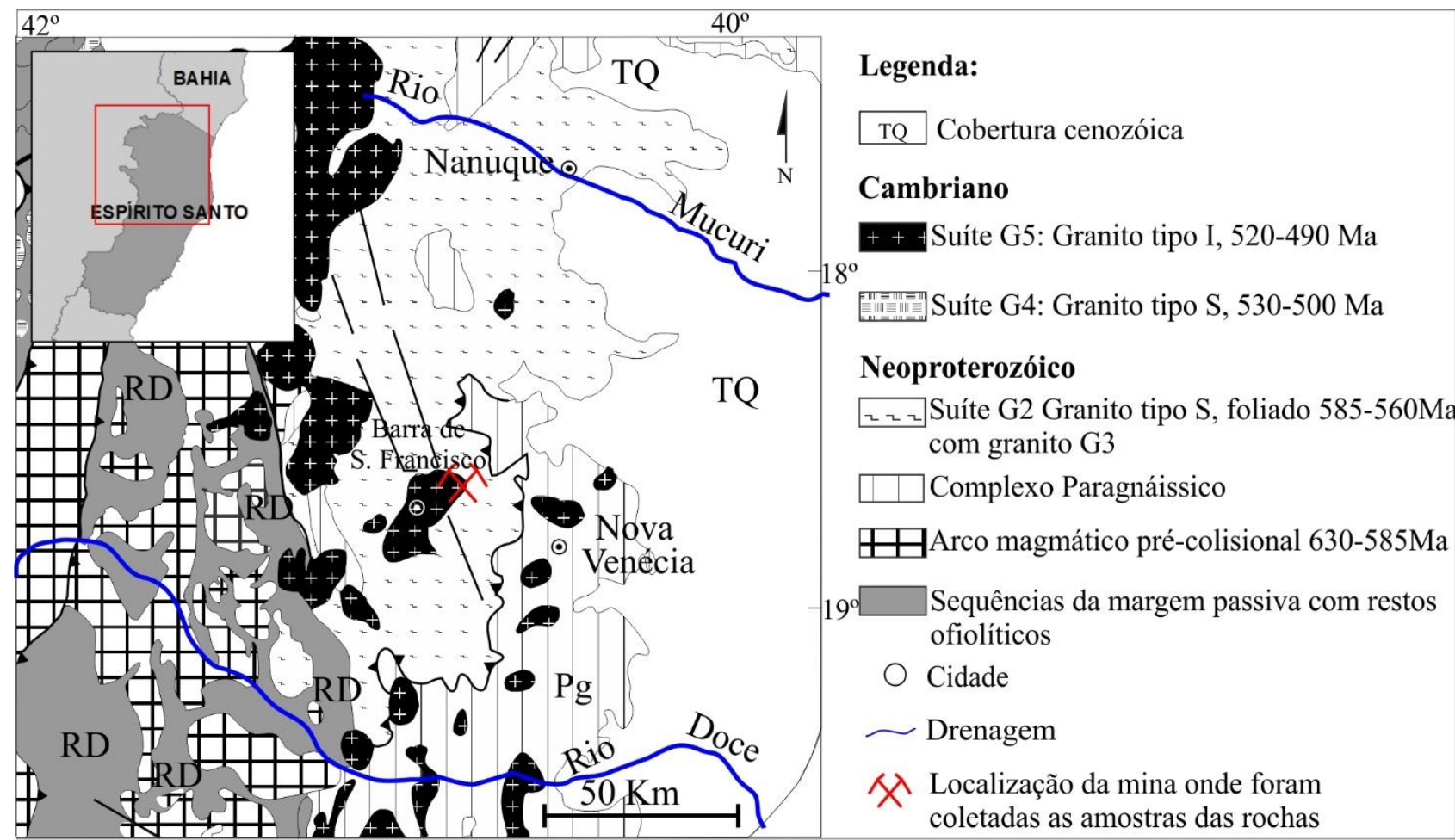

Figura 2 - Mapa geológico da porção sudeste do Orógeno Araçuaí, com a localização da área. (Modificado de PedrosaSoares et al., 2006).

A suíte G5, de maneira geral, é constituída por rochas graníticas do Tipo I, livres da foliação regional, cuja ocorrência se limita ao núcleo do orógeno. Estas intrusões podem conter fácies charnockíticas e enderbíticas. $\mathrm{Na}$ porção sul do orógeno, em decorrência da exposição de nível crustal mais profundo, são comuns os plútons zonados que mostram núcleos (raízes) de composição básica. A composição predominante das intrusões G5 varia de monzogranito a sienogranito, geralmente porfirítico com frequentes enclaves máficos e eventuais xenólitos de rocha encaixante. Nesse contexto, os processos de diferenciação magmática dos núcleos de composição máfica, resultaram na formação do quartzo sienito presente no corpo intrusivo.

A Suíte G2 engloba os produtos da granitogênese sin-colisional que, conforme CPRM (2007b segundo Pedrosa-Soares et al. 2006), é composta por granitos peraluminosos, Tipo-S, regionalmente afetados pela deformação dúctil do estágio sin-colisional do Orógeno Araçuaí, embora localmente os grandes batólitos possam mostrar porções que não foram afetadas por tal evento deformacional.

Estão representadas pelas unidades Ataléia, Carlos Chagas e Montanha, entretanto, cuja a importância nesse artigo se dá apenas para contextualizar regionalmente o quartzo sienito estudado.

\section{ASPECTOS GEOLÓGICOS DA MINA}

A lavra da área de estudo situa-se na região noroeste do Estado do Espírito Santo, no município de Barra de São Francisco sendo localizada na porção central do corpo intrusivo Aimorés (G5), mais precisamente no encurtamento central, aproximando-se da borda norte da ocorrência (Figura 3). As rochas sieníticas com hiperstênio pertencem à Suíte G5 e ocorrem encaixadas em biotita-granada gnaisses com sillimanita da Suíte Carlos Chagas, cujas foliações mais proeminentes, estão associadas à principal deformação NWSE (Faixa de lineamentos Colatina ou Vitória Ecoporanga). 


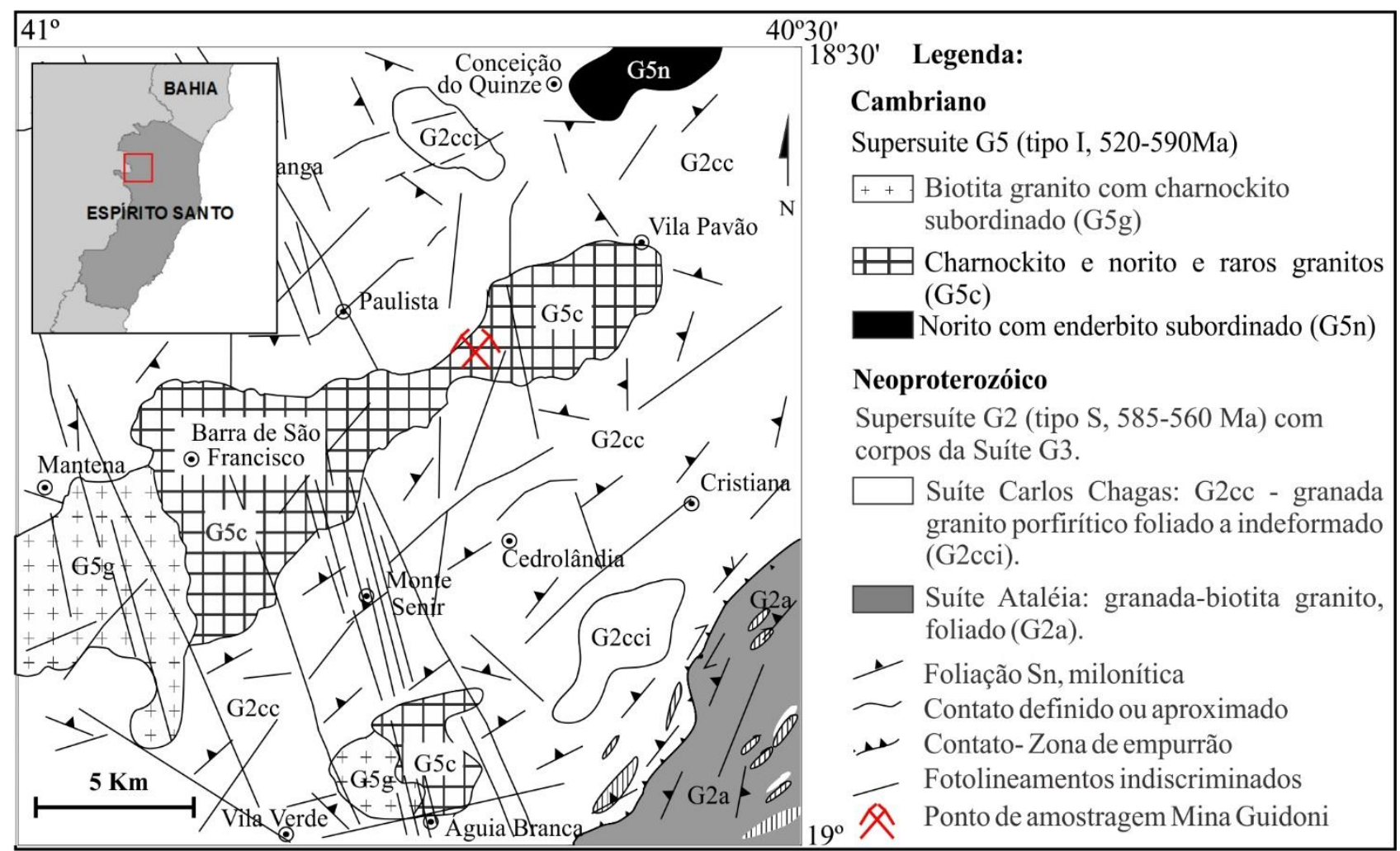

Figura 3 - Mapa geológico simplificado da Folha Mantena-MG (Mod. de Pedrosa-Soares et al., 2006).

$\mathrm{Na}$ pedreira, especificamente, ocorrem apenas quartzo sienitos com hiperstênio com colorações gerais verde e bege, variedades comercializadas como rochas para revestimento denominadas Butterfly Green e Butterfly Beige, que terão suas análises petrográficas detalhadas na caracterização tecnológica. A coloração da variedade bege pode variar para amarela devido ao grau de alteração e ser comercializada como Butterfly Gold.
A distribuição das variedades na mina é caótica com contatos gradacionais entre eles dificultando o planejamento das atividades de extração (Figura 4). Estas colorações peculiares são atribuídas ao feldspato potássico (microclínio). No caso específico das rochas de coloração verde a CPRM (2007b), em seu relatório da Folha Mantena - MG, atribui a cor verde dos feldspatos potássicos aos centros de cor impostos por inclusões de $\mathrm{CO}_{2}$.

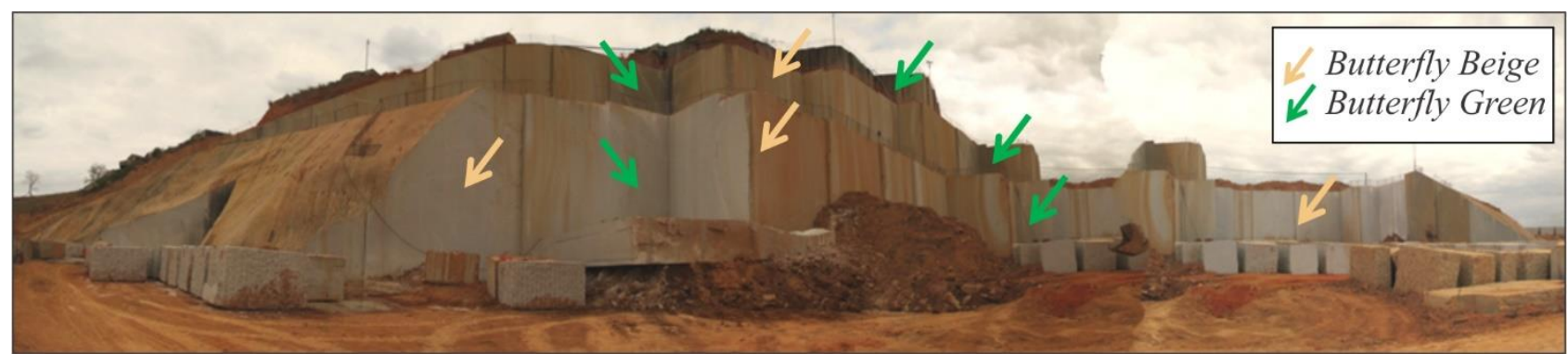

Figura 4 - Foto panorâmica da pedreira, com setas mostrando a distribuição irregular dos tipos de rochas.

Foi possível identificar uma orientação por fluxo ígneo, nos contatos entre a suíte Intrusiva Aimorés e a Suíte Carlos Chagas, relacionado ao campo de esforços causado pelo alojamento do corpo intrusivo, o que, pode ser confundido com uma foliação regional (Figura 5A).

A lavra em questão é realizada pelo método das bancadas altas e feita de forma descendente, utilizado pelas condições de facilidade oferecidas pelas baixas declividade e amplitude morfológicas do maciço.

É comum, nos contatos com as encaixantes, um aumento significativo na quantidade de granada presente nas rochas da suíte na qual se inserem as rochas em estudo, com porções localizadas da rocha de aspecto pegmatóide e com discreta foliação de fluxo plástico (Figura 5B). Ocorre ainda a presença de semi-anéis de feldspato potássico que envolvem os cristais de microclínio e dão o formato ovóide a eles 
(Figura 5C e Figuras 6A, B, C). Agregados minerálicos de granada são frequentemente encontrados em associação a xenólitos básicos centimétricos ao longo da intrusão (Figura 6D).
O formato ovóide pode ser verificado em todas as variedades extraídas na mina e dão, quando aos pares, os contornos que lembram a forma de uma borboleta (Butterfly).

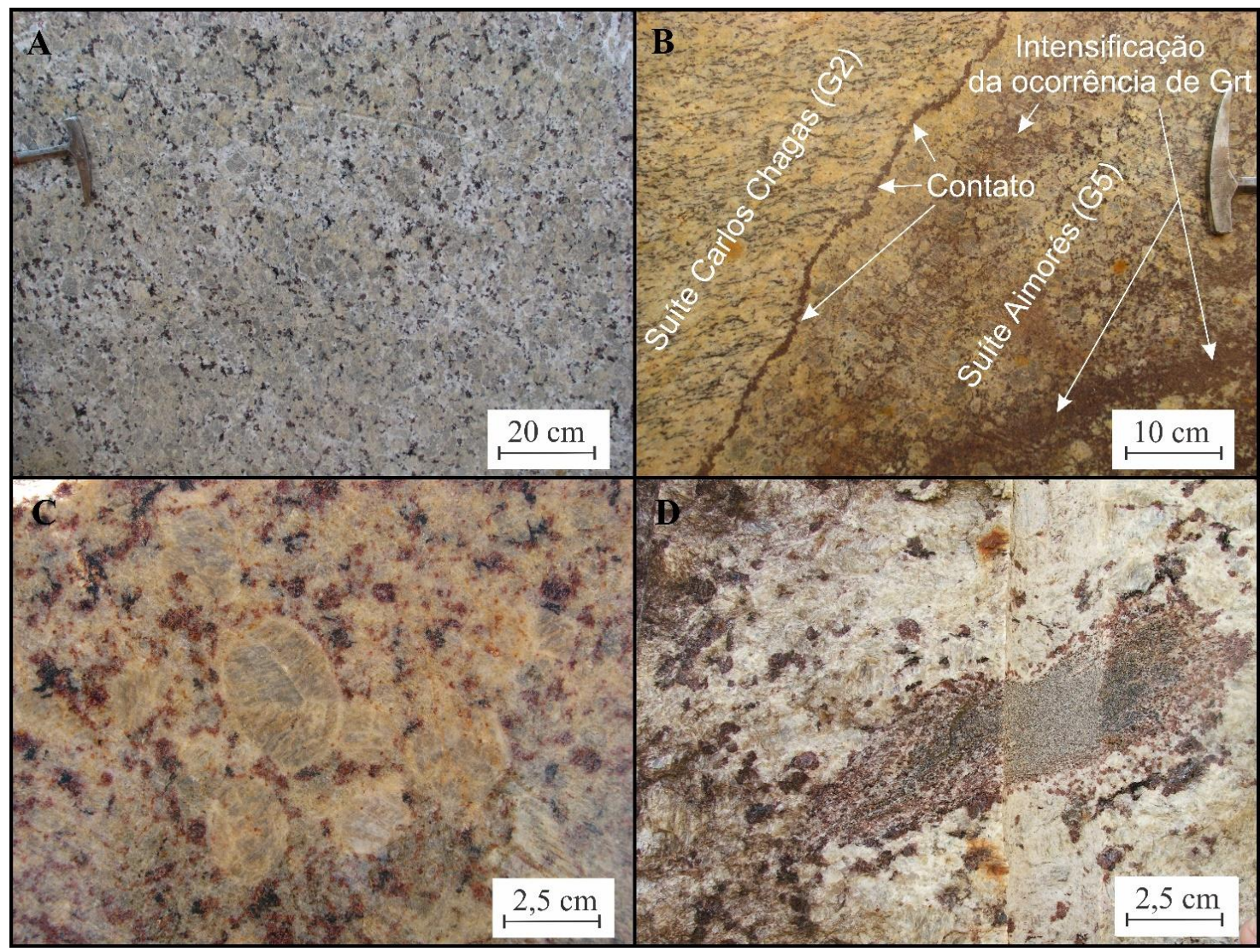

Figura 5 - Feições geológico-petrográficas presentes na pedreira.

Legenda: A) A rocha não apresenta feições de deformação dúctil; B) Concentração de granada (Grt) nas zonas de contato com as encaixantes; C) Feldspato potássico com formato ovóide e semi-anéis também compostos por feldspato potássico; D) Xenólito básico parcialmente assimilado, destacando a quantidade de granada presente.

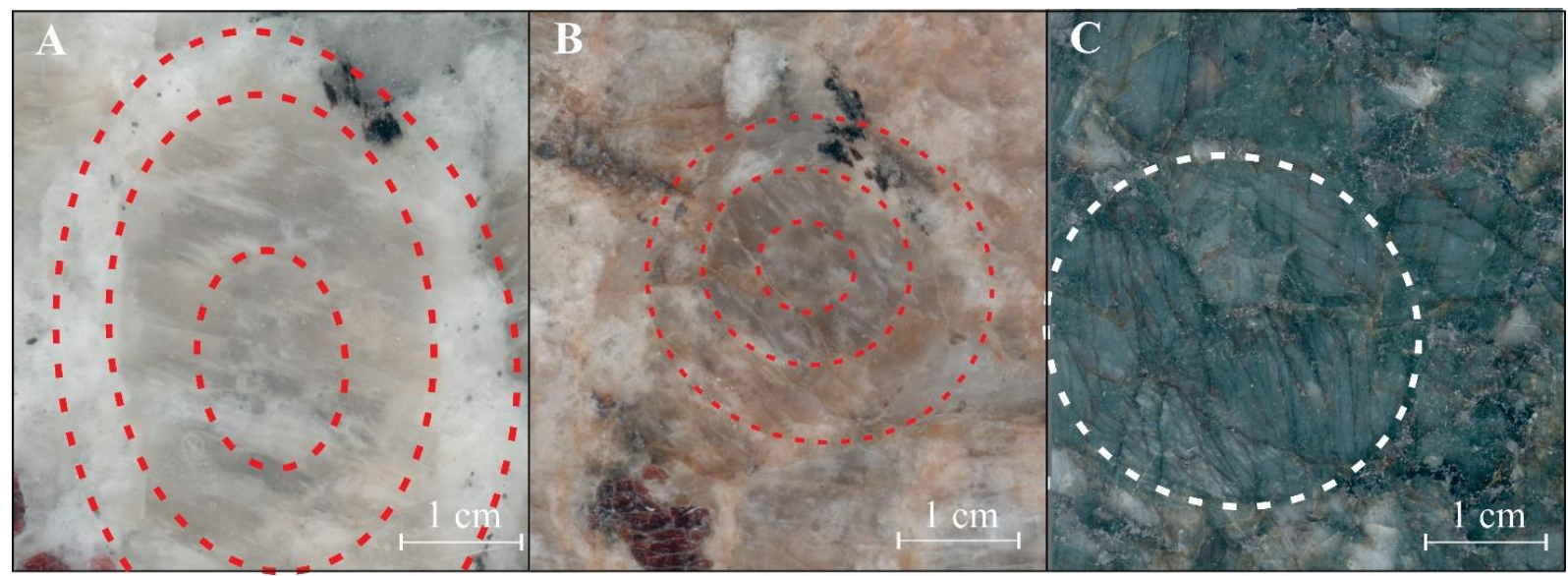

Figura 6 - Ilustração dos cristais de microclínio ovóides e da textura de reação.

Legenda: Os círculos vermelhos indicam a coroa de reação: A) Beige, B) Gold e no C) Green o círculo branco demonstra a forma ovóide do microclínio.

\section{RESULTADOS E DISCUSSÃO}

\section{Aspectos Petrográficos}

As duas rochas estudadas apresentam grande similaridade composicional, textural e estrutural, diferenciadas pelas diferentes colorações. São rochas com texturas inequigranulares, hipidiomórficas, de granulações 
grossas a porfiríticas variando de $0,2 \mathrm{~cm}$ a 4,5 $\mathrm{cm}$, estrutura isotrópica, compostas basicamente por microclínio, plagioclásio (oligoclásio), quartzo, granada, biotita e hiperstênio (Tabela 2). Os megacristais de microclínio representam mais de $50 \%$ dos minerais presentes em cada uma das rochas e podem chegar a $4,5 \mathrm{~cm}$ de eixo maior enquanto que a matriz dessas rochas apresenta cristais com dimensões que variam entre $0,5 \mathrm{~cm}$ e $2,0 \mathrm{~cm}$.

Tabela 2 - Resumo das características petrográficas das rochas da pedreira estudada.

\begin{tabular}{|c|c|c|c|c|}
\hline \multicolumn{2}{|c|}{ Características Petrográficas } & Butterfly Beige & Butterfly Gold & Butterfly Green \\
\hline \multicolumn{2}{|l|}{ Coloração Geral } & Bege & Amarelo & Verde \\
\hline \multicolumn{2}{|c|}{ Estrutura/textura } & \multicolumn{3}{|c|}{ Isotrópica/ Inequigranular } \\
\hline \multicolumn{2}{|c|}{ Granulação relativa } & \multicolumn{3}{|c|}{ Grossa a porfirítica } \\
\hline \multirow{7}{*}{ 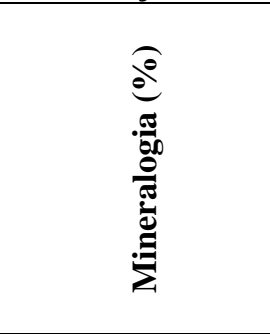 } & Quartzo & 11 & 15 & 13 \\
\hline & Microclínio & 62 & 58 & 58 \\
\hline & Plag. (oligoclásio) & 22 & 20 & 20 \\
\hline & Biotita & 2 & 2 & 2 \\
\hline & Granada & 2 & 4 & 6 \\
\hline & Hiperstênio & 1 & 1 & 1 \\
\hline & $\begin{array}{l}\text { Acessórios (apatita, } \\
\text { zircão) }\end{array}$ & \multicolumn{3}{|c|}{ traços } \\
\hline Granulação (cm) & $\begin{array}{l}\text { Variação } \\
\text { (predominância) }\end{array}$ & 0,2 a $4,5(1$ a 4$)$ & $0,2$ a 4,5 (1 a 4$)$ & 0,2 a $4(1$ a 4$)$ \\
\hline \multicolumn{2}{|c|}{ Alteração Mineral } & Incipiente & Moderada & Incipiente \\
\hline \multirow{4}{*}{$\begin{array}{c}\text { Microfissuras } \\
\text { (predomínio) }\end{array}$} & Tipo & intra-/intergranular & intra-/intergranular & intra-/intergranulai \\
\hline & Aberta/fechada & aberta & aberta & aberta \\
\hline & Preenchimento & $\mathrm{Fe}(\mathrm{OH})_{2} /$ Ser. & $\mathrm{Fe}(\mathrm{OH})_{2} /$ Ser. & $\mathrm{Fe}(\mathrm{OH})_{2} / \mathrm{Ser}$. \\
\hline & Grau & baixo & médio & alto \\
\hline \multicolumn{2}{|c|}{ Classificação Petrográfica (QAP) } & \multicolumn{3}{|c|}{ Quartzo sienito com hiperstênio } \\
\hline
\end{tabular}

Legenda: Ser) Sericita; QAP) Quartzo; Álcali feldspato; Plagioclásio.

As rochas apresentam-se, no geral, microfissuradas e/ou pertitizadas. Entretanto, tais feições estão restritas aos cristais de microclínio que, em geral, representam mais de $50 \%$ da composição de cada uma das rochas estudadas.

No Butterfly Green (Figura 7A), os cristais de microclínio (cristais com maiores dimensões e ocorrência nas rochas) apresentam microfissuras preenchidas por hidróxido ferroso (coloração verde).

O Butterfly Beige apresenta processos de pertitização com pertitas dos tipos manchas e veios e de forma incipiente apresenta microfissuras preenchidas por hidróxido ferroso.

A presença das pertitas nos minerais de microclínio são responsáveis pela coloração bege geral da rocha (Figura 7B).

Já o Butterfly Gold, produto da alteração da variedade Butterfly Beige, além da oxidação das biotitas, apresenta a mudança do hidróxido ferroso $\left[\mathrm{Fe}(\mathrm{OH})_{2}\right]$, presente em suas microfissuras, para hidróxido férrico $\left[\mathrm{Fe}(\mathrm{OH})_{3}\right]$ devido à mudança de carga do $\mathrm{Fe}^{2+}$ para $\mathrm{Fe}^{3+}$ provocada pela ação intempérica (Figura 7C).

Os cristais de quartzo, anédricos, sem extinção ondulante (corroborando a ausência de deformação dúctil), a exemplo dos cristais de microclínio, também apresentam microfissuras preenchidas por hidróxido de ferro (Figura 8A).

Os cristais de microclínio, anédricos, com formas ovóides visualizáveis com clareza apenas na amostra de mão, são geralmente micropertíticos, apresentando-se por vezes mimerquíticos e com algumas relações de intercrescimento com o quartzo definindo a textura granofírica para alguns cristais (Figura 8B), exceto para a variedade Green onde não apresenta nenhuma dessas feições.

Um processo de sericitização incipiente pode ser observado em seus cristais, principalmente na variedade Butterfly Gold.

Os cristais de plagioclásio (oligoclásio) são anédricos e com geminação polissintética (Figura 9C). É possível observar também, na 
variedade Butterfly Gold, cristais de biotita em processo de cloritização (Figura 8C), diferenciando-os do que se pode observar nas variedades Beige e Green (Figura 8D) onde apresentam pleocroísmo marrom esverdeado, sem qualquer alteração.

Os cristais de hiperstênio apresentam pleocroísmo verde e relevo alto, mas encontram-se em pequenas quantidades nas lâminas descritas.

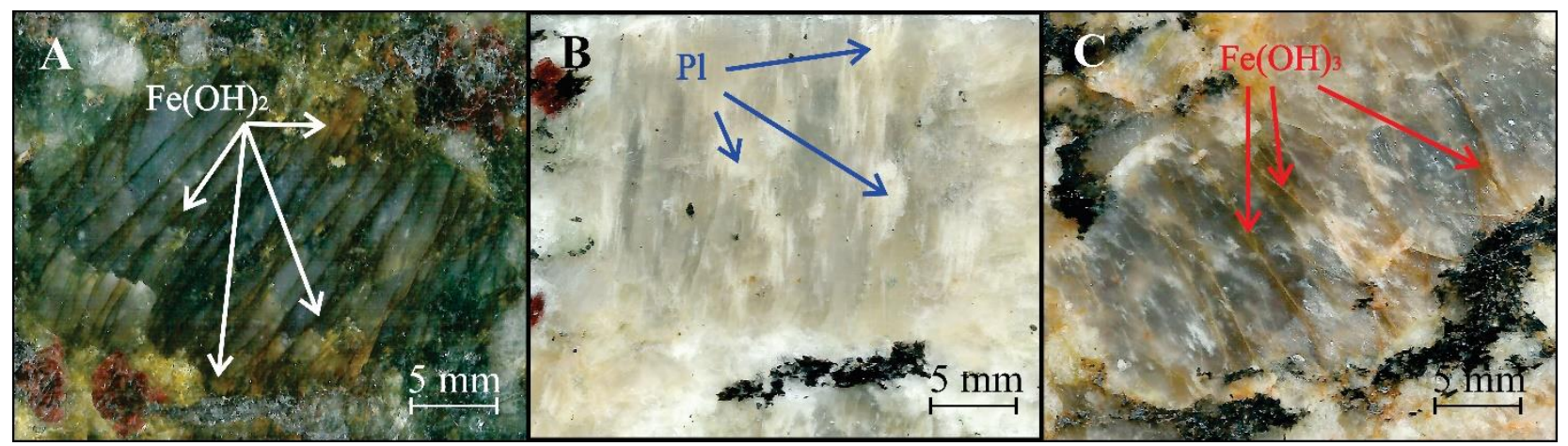

Figura 7 - Fotografias obtidas com o uso de uma lupa binocular óptica para ilustração das microfissuras preenchidas por hidróxidos e das pertitas presentes nos minerais, sobretudo, de microclínio.

Legenda: A) Butterfly Green com microfissuras preenchidas por hidróxido ferroso; B) Butterfly Beige com processo de pertitização; C) Butterfly Gold com processo de pertitização e microfissuras preenchidas por hidróxido férrico.

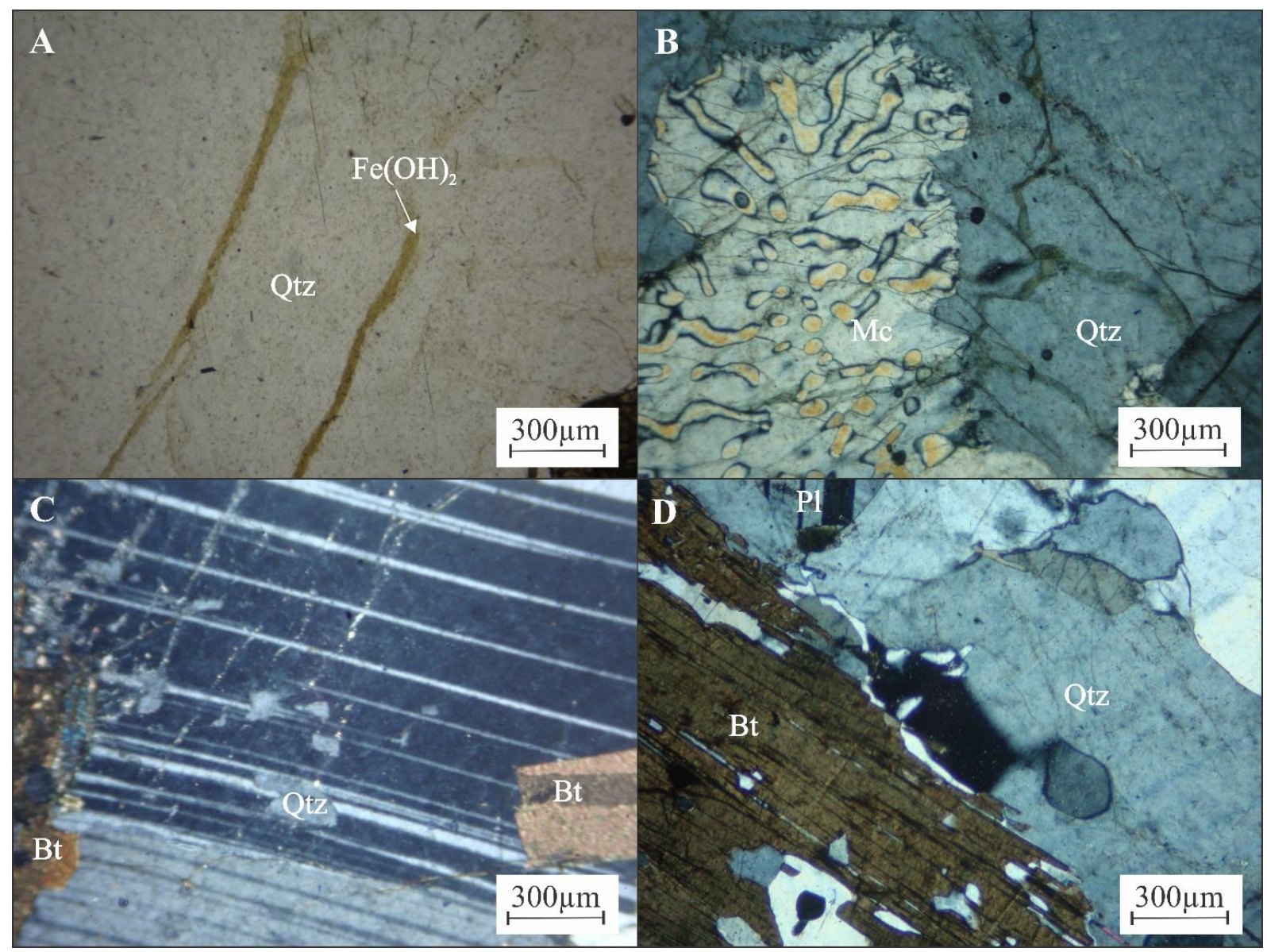

Figura 8 - Fotomicrografias das rochas estudadas (quartzo sienitos com hiperstênio).

Legenda: Nicóis cruzados. Qtz) Quartzo; Bt) Biotita; Pl) Plagioclásio (oligoclásio); Mi) Microclínio; Fe( $\mathrm{OH})_{2}-$ hidróxido ferroso.

\section{Caracterização Físico-mecânica}

Os resultados dos ensaios de caracterização realizados (Tabelas 3 e 4) mostram grande homogeneidade entre as duas rochas com valores próximos aos dos requisitos mínimos e máximos sugeridos para rochas graníticas pela ABNT NBR 15844 (ABNT, 2010f).

Os resultados da caracterização físicomecânica são apresentados graficamente na figura 9. 
Tabela 3 - Resultados dos ensaios de caracterização tecnológica.

\begin{tabular}{|c|c|c|c|c|c|}
\hline \multirow{2}{*}{\multicolumn{3}{|c|}{ Ensaio }} & \multicolumn{2}{|c|}{ Litotipos } & \multirow{2}{*}{$\begin{array}{c}\text { NBR 15844 } \\
(A B N T, 2010)\end{array}$} \\
\hline & & & Butterfly Beige & Butterfly Green & \\
\hline \multirow{6}{*}{ 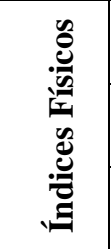 } & \multirow{2}{*}{$\begin{array}{l}\text { Densidade } \\
\text { aparente }\end{array}$} & $\mathrm{kg} / \mathrm{m}^{3}$ & 2671 & 2685 & Mín. $2550 \mathrm{~kg} / \mathrm{m}^{3}$ \\
\hline & & Desvio padrão & 20,24 & 15,45 & - \\
\hline & \multirow{2}{*}{ Porosidade } & $\%$ & 0,61 & 0,52 & Máx. 1,0 \% \\
\hline & & Desvio padrão & 0,20 & 0,07 & - \\
\hline & \multirow{2}{*}{$\begin{array}{l}\text { Absorção d'água } \\
\text { aparente }\end{array}$} & $\%$ & 0,23 & 0,19 & Máx. 0,4\% \\
\hline & & Desvio padrão & 0,03 & 0,03 & - \\
\hline \multirow{4}{*}{ 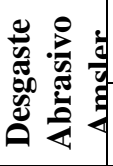 } & \multirow{2}{*}{ Ciclo de 500m } & $\mathrm{mm}$ & 1,15 & 1,00 & - \\
\hline & & Desvio padrão & 0,04 & 0,01 & - \\
\hline & \multirow{2}{*}{ Ciclo de $1000 \mathrm{~m}$} & $\mathrm{~mm}$ & 2,19 & 1,87 & Máx. 1,0 mm \\
\hline & & Desvio padrão & 0,08 & 0,12 & - \\
\hline \multirow{8}{*}{ 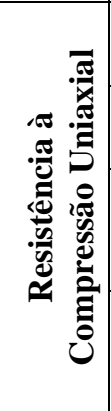 } & \multirow{2}{*}{ Seco } & $\mathrm{MPa}$ & 112,2 & 109,5 & \multirow{6}{*}{ Mín. $100 \mathrm{MPa}$} \\
\hline & & Desvio padrão & 5,0 & 5,0 & \\
\hline & \multirow{2}{*}{ Saturado } & $\mathrm{MPa}$ & 95,7 & 95,2 & \\
\hline & & Desvio padrão & 9,5 & 7,1 & \\
\hline & \multirow{2}{*}{$\begin{array}{c}\text { Após } \\
\text { congelamento e } \\
\text { degelo }\end{array}$} & $\mathrm{MPa}$ & 99,0 & 97,6 & \\
\hline & & Desvio padrão & 4,7 & 5,7 & \\
\hline & \multirow{2}{*}{$\begin{array}{l}\text { Coeficiente de } \\
\text { enfraquecimento } \\
(\mathrm{K})\end{array}$} & (Congelamento e degelo/Natural) & 0,88 & 0,89 & - \\
\hline & & (Congelamento e degelo/Saturado) & 1,03 & 1,02 & - \\
\hline \multirow{8}{*}{ 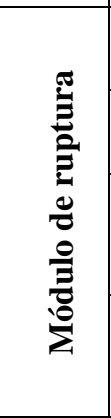 } & \multirow{2}{*}{ Seco } & $\mathrm{MPa}$ & 8,03 & 4,07 & \multirow{6}{*}{ Mín. $10 \mathrm{MPa}$} \\
\hline & & Desvio padrão & 0,70 & 1,09 & \\
\hline & \multirow{2}{*}{ Saturado } & $\mathrm{MPa}$ & 5,63 & 5,03 & \\
\hline & & Desvio padrão & 0,94 & 0,32 & \\
\hline & \multirow{2}{*}{$\begin{array}{c}\text { Após } \\
\text { congelamento e } \\
\text { degelo }\end{array}$} & $\mathrm{MPa}$ & 7,64 & 4,56 & \\
\hline & & Desvio padrão & 1,44 & 0,95 & \\
\hline & \multirow{2}{*}{$\begin{array}{l}\text { Coeficiente de } \\
\text { enfraquecimento } \\
(\mathrm{K})\end{array}$} & (Congelamento e degelo/Natural) & 0,95 & 1,12 & - \\
\hline & & (Congelamento e degelo/Saturado) & 1,36 & 0,91 & - \\
\hline
\end{tabular}

Tabela 4 - Resultados da velocidade de propagação de ondas ultrassônicas.

\begin{tabular}{c|l|c|c}
\hline \multicolumn{2}{c|}{ Ensaio } & \multicolumn{2}{c}{ Velocidades (m/s) } \\
\hline \multirow{2}{*}{ Tipo } & \multicolumn{1}{c|}{ Condição } & Butterfly Beige & Butterfly Green \\
\hline \multirow{2}{*}{$\begin{array}{c}\text { Resistência à } \\
\text { Compressão Uniaxial }\end{array}$} & Seco & 4402 & 3395 \\
\cline { 2 - 4 } & Saturado & 5316 & 5368 \\
\cline { 2 - 4 } & Após congelamento e degelo & 4990 & 3513 \\
\hline \multirow{4}{*}{ Módulo de ruptura } & Seco & 4309 & 2908 \\
\cline { 2 - 4 } & Saturado & 5234 & 3916 \\
\cline { 2 - 4 } & Após congelamento e degelo & 4464 & 3199 \\
\hline
\end{tabular}

As relações de contato entre os minerais nas rochas estudadas são definidas por contatos sinuosos devidos às formas ovóides dos feldspatos alcalinos, contatos parcialmente retilíneos atribuídos aos cristais de plagioclásio e contatos engrenados atribuídos aos cristais de biotita, granada e hiperstênio. Minerais acessórios como apatitas e zircões são encontrados como inclusões nos cristais de biotita, microclínio, plagioclásio e quartzo.

Com relação aos valores de absorção d'água e porosidade aparentes (Tabela 3; Figura 9A), não há diferença expressiva entre as rochas (aprox. 0,1\%) ficando ambas abaixo dos valores sugeridos como limítrofes para rochas graníticas pela norma ABNT NBR 15844 (ABNT, 2010f), ou seja, de $0,4 \%$ e $1,0 \%$ respectivamente. Isso indica, a princípio, que as variedades podem ser utilizadas em ambientes úmidos como banheiros e pias.

Como as microfissuras no Butterfly Green em geral são dos tipos intra- e intergranulares, e estão restritas basicamente aos cristais de microclínio, elas não geram variações nos 
valores de porosidade e absorção d'água para estas rochas.

Entretanto, como os cristais de microclínio perfazem mais de $50 \%$ da composição dos litotipos estudados e são os cristais que apresentam as maiores dimensões, o maior grau de microfissuramento na variedade Green pode acarretar importantes variações nos resultados de resistência mecânica para as rochas ensaiadas.

No tocante a densidade, ambas as rochas superam os $2.550 \mathrm{~kg} / \mathrm{m}^{3}$ requeridos pela norma ABNT NBR 15844 (ABNT, 2010f), com 2671 $\mathrm{kg} / \mathrm{m}^{3}$ para o Butterfly Beige e $2685 \mathrm{~kg} / \mathrm{m}^{3}$ para o Butterfly Green. Ao analisar a tabela 5, elaborada com base nas composições mineralógicas identificadas das rochas em estudo, podemos perceber que as densidades dos minerais (a granada, por exemplo) e as porcentagens com que esses minerais aparecem influenciam na densidade final das rochas.

No entanto, supõe-se que, o volume de microfissuras preenchidas com o hidróxido de ferro (II) ou hidróxido ferroso $\left[\mathrm{Fe}(\mathrm{OH})_{2}\right]$ presente no Butterfly Green (Grau alto, tabela 1) e no Beige (Grau baixo, tabela 1), além do teor de granada pouco superior da primeira rocha, sejam os maiores responsáveis pela densidade aparente um pouco mais elevada para o Green em relação ao Beige (Figura 9B).

Tabela 5 - Relação de densidades e porcentagens minerais.

\begin{tabular}{l|c|c|c}
\hline \multirow{2}{*}{ Minerais e compostos } & Densidades $\left(\mathbf{k g} / \mathbf{c m}^{\mathbf{3}}\right) \mathbf{e}$ & \multicolumn{2}{c}{ Porcentagens minerais $(\%)$} \\
\cline { 3 - 4 } & referências & Butterfly Beige & Butterfly Green \\
\hline Plagioclásio & 2620 & 22 & 20 \\
\hline Granada (almandina) & 4190 & 2 & 6 \\
\hline Biotita & 3090 & 2 & 2 \\
\hline Hiperstênio & 3550 & 1 & 1 \\
\hline Microclínio & 2590 & 62 & 58 \\
\hline Quartzo & 2620 & 11 & 13 \\
\hline $\mathrm{Fe}(\mathrm{OH})_{2}$ preenchendo fraturas & 3400 & Fraturamento baixo & Fraturamento alto \\
\hline
\end{tabular}

Já, no caso da abrasão Amsler as rochas apresentam desgastes relativamente elevados com 2,19 mm para o Butterfly Beige e 1,87 mm para o Butterfly Green (Tabela 3; Figura 9C), bem acima do valor de $1,0 \mathrm{~mm}$ tido como requisito para granitos (ABNT NBR 15844; ABNT, 2010f). Os desgastes relativamente elevados se coadunam, em grande parte, com as características petrográficas das referidas rochas dadas pelo baixo teor de quartzo, grau de microfissuramento mais ou menos pronunciado (em muitos casos com planos abertos e preenchidos por minerais secundários) e granulação média-grossa, a qual conduz a contatos inter-minerais mais frouxos. Em particular, a presença de microfissuras e granulação grossa facilitam a liberação de micropartículas durante processos de abrasão com consequente maior desgaste. A resistência à abrasão pouco maior oferecida pela variedade Green pode estar associada à sua maior quantidade de quartzo (13\%) em relação ao Beige (11\%), bem como de seu menor grau de oxidação aparente. Os valores de desgaste, acima do sugerido como limítrofe pela ABNT NBR 15844 (ABNT, 2010f), indicam que é preciso ter cautela ao aplicar estas rochas em ambientes com alto tráfego sob o risco de perda acelerada do polimento.

Com relação a compressão uniaxial (Tabela 3; Figura 9D), os valores de tensão de ruptura para as rochas na condição seca estão dentro do que se sugere como limítrofe para rochas graníticas pela norma específica (mínimo 100 $\mathrm{MPa})$.

Nota-se uma pequena diferença na resistência a compressão uniaxial na condição seca entre o Beige (112,2 MPa) e o Green (109,5 MPa) que pode estar associada à maior quantidade de cristais de microclínio na variedade Beige e o fato destes minerais possuírem pertitas (o que não ocorre na variedade Green) ocasionado sua maior resistência.

Essa pequena diferença na resistência se repete também nas condições de ensaio saturado e após congelamento e degelo onde ocorre, para ambas as rochas, um decréscimo no valor de resistência (maior na condição saturado) devido ao enfraquecimento hidráulico. 


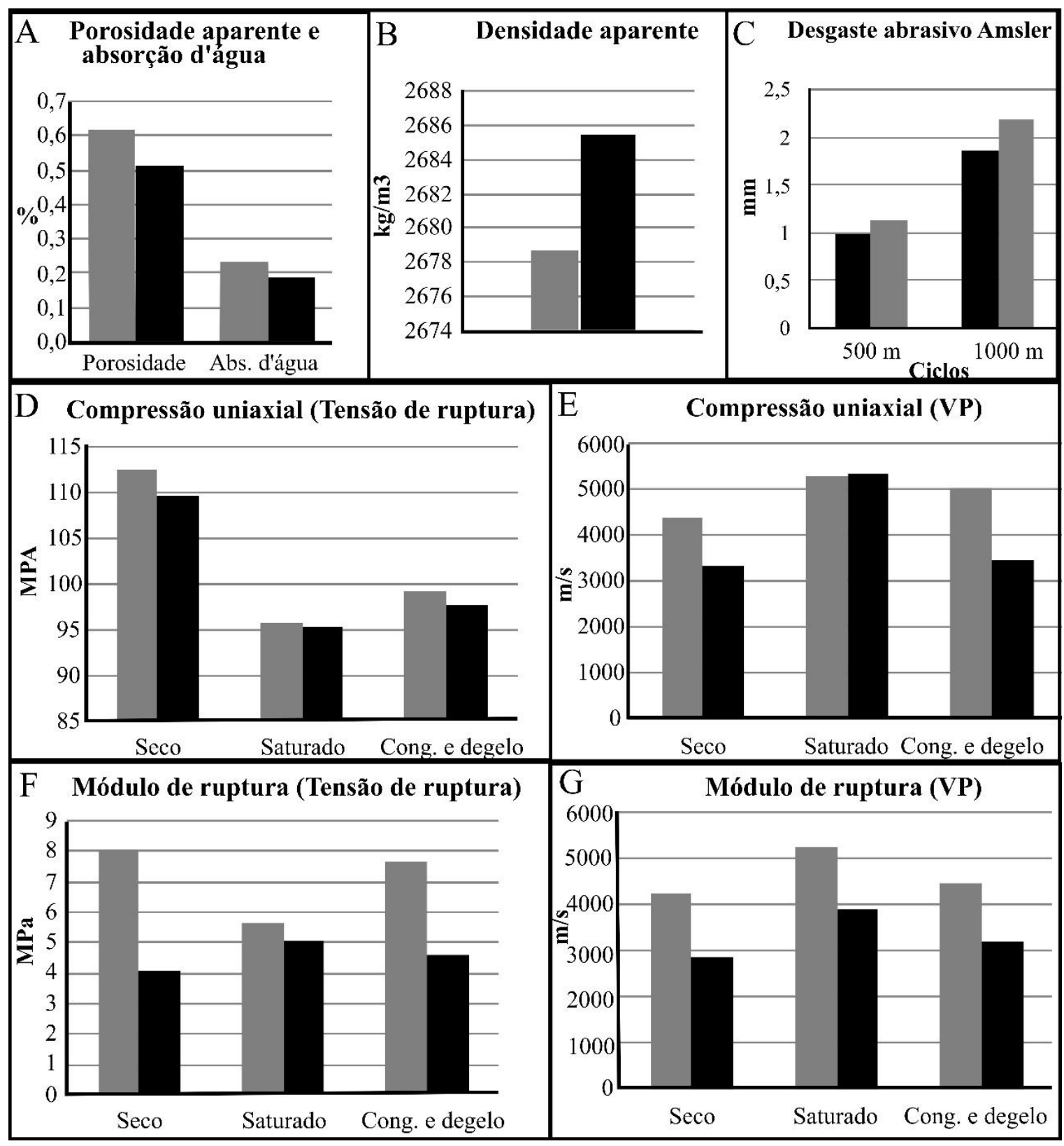

Figura 9 - Representação gráfica dos resultados dos ensaios da caracterização tecnológica.

Legenda: Barra cinza - Butterfly Beige; Barra preta - Butterfly Green; VP - Velocidade de propagação de ondas ultrassônicas.

Os valores de compressão uniaxial mostram que estas rochas devem, a princípio, ser aplicadas com cautela como elementos estruturais por apresentarem valores resistência muito próximos da tensão de ruptura mínima sugerida como limítrofe.

No ensaio de flexão em três pontos ou módulo de ruptura (Tabela 3; Figura 9F) os resultados mostraram valores abaixo dos sugeridos como limítrofes para rochas graníticas (10 $\mathrm{MPa})$ para ambas as rochas e para todas as condições de ensaio. Com exceção da condição saturado, os resultados obtidos pelo Butterfly Green (condição seco 8,03 MPa e condição após congelamento e degelo 7,64 $\mathrm{MPa}$ ) representam praticamente metade daqueles obtidos pelo Butterfly Beige (condição seco 4,07 MPa e condição Após congelamento e degelo 4,56 MPa).

A maior quantidade de cristais de microclínio na variedade Beige, a presença de pertitas em sua estrutura e seu baixo grau de microfissuramento (Tabela 2) em relação à variedade Green são fatores que justificam as diferenças de resistência. Os resultados demonstram que a aplicação destes materiais em fachadas com insertos metálicos ou em pisos elevados, pode acarretar problemas se os cálculos para o dimensionamento das placas não forem realizados de forma adequada, considerando-se os valores de ensaio de flexão. 
Os coeficientes de enfraquecimento $\mathrm{K}$ calculados, para o ensaio de compressão uniaxial e módulo de ruptura, com base nas condições de ensaio (seco, saturado e após o congelamento e degelo) ficaram todos muito próximos de 1 (Tabela 3), valores que, segundo nota da norma NBR 15844 (ABNT, 2010b) são inexpressivos. Logo, os ciclos de congelamento e degelo não influenciaram na resistência mecânica das rochas, fator positivo à aplicação destas em ambientes com temperaturas baixas.

Os valores de velocidade de propagação de ondas ultrassônicas (Tabela 4; Figura 9E e G) mostram-se para o Butterfly Beige, nos ensaios na condição com corpos de prova secos, superiores cerca de $1000 \mathrm{~m} / \mathrm{s}$ em relação ao Green devido ao seu menor grau de microfissuramento. $\mathrm{Na}$ condição de ensaio saturado as velocidades de propagação de ondas ultrassônicas praticamente se igualam para as duas rochas pois a água funciona como preenchimento para as microfissuras no Butterfly Green aumentando às velocidades relacionadas à esta variedade.

As velocidades de propagação de ondas ultrassônicas medidas no ensaio de congelamento e degelo, logo após o último degelo, mostram-se superiores às velocidades medidas nos ensaios na condição seco devido à saturação em água imposta às rochas durante os ciclos de congelamento.
Em geral, as diferenças de resistência físicomecânica entre o Butterfly Beige e o Butterfly Green são justificáveis pelos graus de microfissuramento (Tabela 2: Beige - Baixo; Green - Alto) e pela presença do processo de pertitização no Butterfly Beige, ou seja, o menor grau de microfissuramento e as pertitas, fornecem ao Butterfly Beige uma maior resistência mecânica comparando-se ao Green.

\section{Ataque Químico}

Com relação ao brilho, todos os reagentes provocaram perdas nas superfícies das amostras (Tabela 6). Mesmo não provocando as maiores perdas de brilho, o ácido clorídrico $(\mathrm{HCl}) 3 \%$ vv (Figura 10C com 15,3\% de perda) e $18 \%$ vv (Figura 10D com 15,3\% de perda) foram os únicos que provocaram no Butterfly Beige perdas de brilho visíveis a olho nu.

No Beige estes reagentes removeram a resina que recobria a superfície e corroeram minerais (granada, biotita e hiperstênio) ao ponto de deixar suas superfícies foscas, mas sem remoção de rocha ou fragmentos de minerais.

A intensidade das alterações químicas é diretamente proporcional ao aumento da concentração de $\mathrm{HCl}$ de $3 \%$ vv para $18 \%$ vv. $\mathrm{Na}$ concentração $18 \%$ vv ocorre a cristalização de sais em algumas microfissuras e as alterações no hiperstênio ficam mais proeminentes.

Tabela 6 - Resultados, em porcentagem, da perda de brilho das rochas no ataque químico.

\begin{tabular}{c|c|c|c|c|c|c|c|c}
\hline Rochas & $\begin{array}{c}\text { KOH } \\
\mathbf{3 0 g} / \mathbf{L}\end{array}$ & $\begin{array}{c}\mathbf{K O H} \\
\mathbf{1 0 0 g} / \mathbf{L}\end{array}$ & $\begin{array}{c}\mathbf{H C l} \\
\mathbf{3 \%}\end{array}$ & $\begin{array}{c}\mathbf{H C l} \\
\mathbf{1 8 \%}\end{array}$ & $\begin{array}{c}\mathbf{N H} \mathbf{~ C l} \\
\mathbf{1 0 0 g} / \mathbf{L}\end{array}$ & $\begin{array}{c}\mathbf{C}_{6} \mathbf{H}_{8} \mathbf{O}_{7} \\
\mathbf{1 0 0 g} / \mathbf{L}\end{array}$ & $\begin{array}{c}\mathbf{C}_{3} \mathbf{H}_{6} \mathbf{O}_{3} \\
\mathbf{5 \%} \% \mathbf{v}\end{array}$ & $\begin{array}{c}\mathbf{N a C l O} \\
\mathbf{2 0 m g} / \mathbf{L}\end{array}$ \\
\hline $\begin{array}{c}\text { Butterfly } \\
\text { Beige }\end{array}$ & $10,2 \%$ & $16,7 \%$ & $15,6 \%$ & $15,3 \%$ & $15,3 \%$ & $16,5 \%$ & $11,9 \%$ & $12,5 \%$ \\
\hline $\begin{array}{c}\text { Green } \\
\text { Buterfly }\end{array}$ & $14,3 \%$ & $16,1 \%$ & $14,0 \%$ & $13,9 \%$ & $13,3 \%$ & $19,2 \%$ & $12,2 \%$ & $11,4 \%$ \\
\hline
\end{tabular}

Legenda: $\mathrm{KOH}$ (Hidróxido de potássio); $\mathrm{HCl}$ (Ácido clorídrico); $\mathrm{NH}_{4} \mathrm{Cl}$ (Cloreto de amônio); $\mathrm{C}_{6} \mathrm{H}_{8} \mathrm{O}_{7}$ (Ácido cítrico); $\mathrm{C}_{3} \mathrm{H}_{6} \mathrm{O}_{3}$ (Ácido lático); $\mathrm{NaClO}$ (Hipoclorito de sódio).

$\mathrm{O}$ reagente que provocou a maior perda de brilho no Butterfly Beige foi o hidróxido de potássio $\mathrm{KOH} \mathrm{100g/l} \mathrm{(Figura} \mathrm{10B),} \mathrm{seguido} \mathrm{do}$ ácido cítrico $\mathrm{C}_{6} \mathrm{H}_{8} \mathrm{O}_{7} \quad 100 \mathrm{~g} / \mathrm{l}$ (Figura $10 \mathrm{~F}$ ) afetando a camada de resina que recobria a superfície do corpo de prova. O hidróxido de potássio está presente em sabões e isto implica, apesar de possuir valores dentro dos sugeridos para os índices físicos, cautela na aplicação deste material em pias e áreas deste revestimento. $\mathrm{O}$ ácido cítrico está presente em frutas cítricas e pode se frequentemente em contato com a rocha gerar perda de brilho localizada. Os demais reagentes (Figuras 10A, $10 \mathrm{E}, 10 \mathrm{G}$ e $10 \mathrm{H}$ ) não provocaram reações perceptíveis a olho nú.

No Butterfly Green o reagente que provocou as maiores alterações estéticas, mesmo não sendo responsável pelas maiores perdas de brilho, também foi o ácido clorídrico em suas duas concentrações $(\mathrm{HCl} \mathrm{3 \%}$ vv $-14,0 \%$ de perda e $\mathrm{HCl} 18 \%$ vv $-13,9 \%$ de perda). $\mathrm{Ou}$ seja, além da perda de brilho produziu intensa descoloração da rocha. 


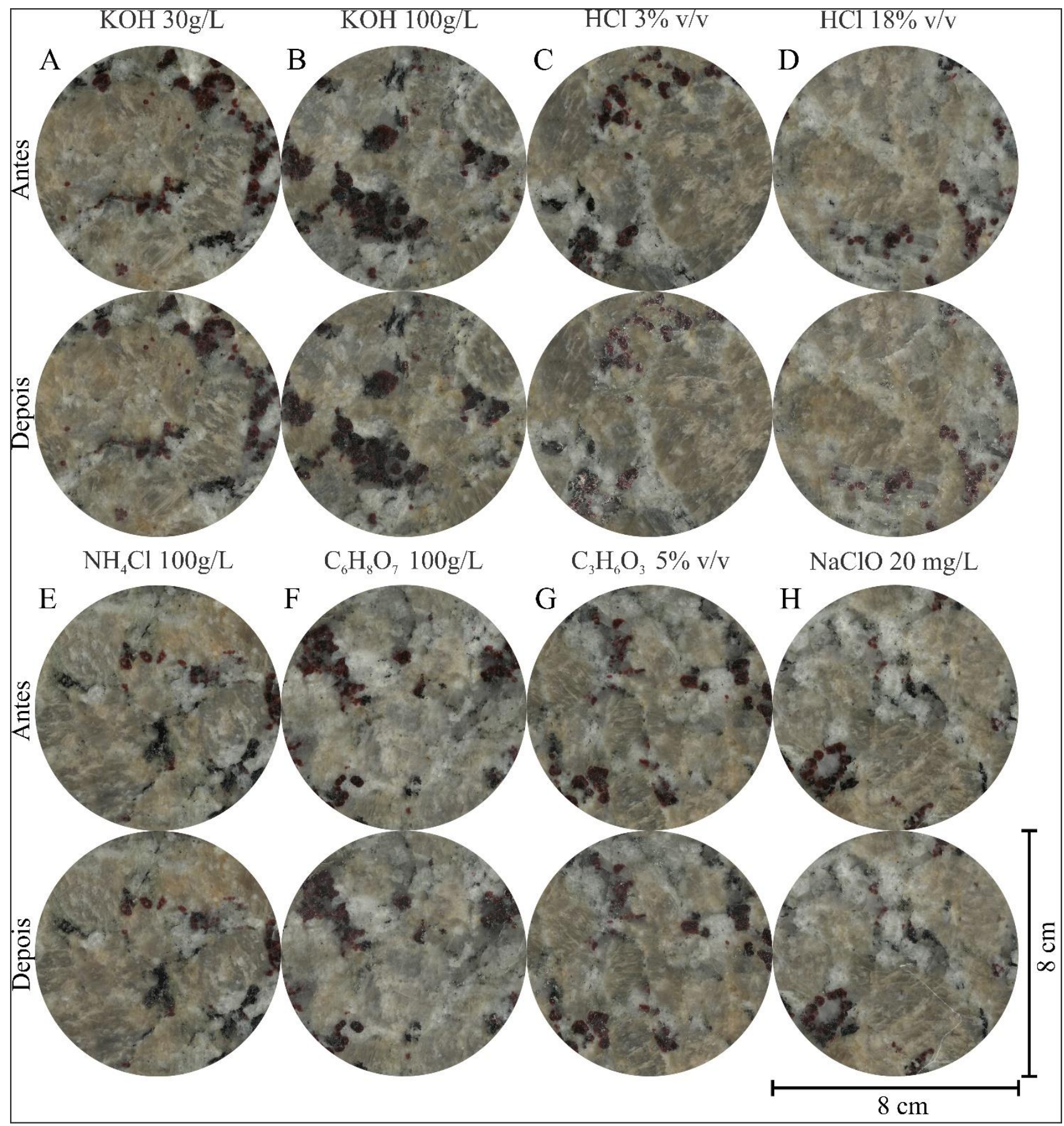

Figura 10 - Corpos de prova do Butterfly Beige submetidos ao ensaio de ataque químico.

Legenda: $\mathrm{KOH}$ (Hidróxido de potássio); $\mathrm{HCl}$ (Ácido clorídrico); $\mathrm{NH}_{4} \mathrm{Cl}$ (Cloreto de amônio); $\mathrm{C}_{6} \mathrm{H}_{8} \mathrm{O}_{7}$ (Ácido cítrico); $\mathrm{C}_{3} \mathrm{H}_{6} \mathrm{O}_{3}$ (Ácido lático); $\mathrm{NaClO}$ (Hipoclorito de sódio).

A relação de aumento da intensidade das reações à medida que aumenta a concentração do referido ácido também é evidenciada para esta variedade do quartzo sienito com hiperstênio estudado.

$\mathrm{O} \mathrm{HCl}$ na concentração 3\% vv (Figura 11C) provocou a remoção parcial do hidróxido ferroso, responsável pelo tom verde dado aos cristais de microclínio, que preenchia as microfissuras desta rocha e por consequência pela cor geral verde deste litotipo.
Já com a concentração $18 \% \quad$ vv $\quad$ o $\quad H C l$ provocou a total perda da cor verde característica da rocha (Figura 11D), removendo todo o hidróxido ferroso que preenchia as microfissuras e planos de clivagem e também afetando cristais de biotita e granada alterando completamente a rocha.

$\mathrm{O}$ reagente que causou a maior perda de brilho no Butterfly Green e a maior entre as duas rochas foi o ácido cítrico $\mathrm{C}_{6} \mathrm{H}_{8} \mathrm{O}_{7} \quad 100 \mathrm{~g} / \mathrm{l}$ (Figura 11F), mas com menor efeito da 
descoloração da superfície da rocha que o ocasionado pelo $\mathrm{HCl}$, removendo a resina e provocando desplacamento de biotitas.

As mesmas considerações feitas para o Butterfly Beige com relação a este reagente se aplicam ao Butterfly Green com um agravante que é a coloração escura da rocha.
Os demais reagentes (Figura 11A, 11B e $11 \mathrm{G}$ e $11 \mathrm{H}$ ), com exceção do $\mathrm{NH}_{4} \mathrm{Cl} 100 \mathrm{~g} / \mathrm{l}$ (Figura 11E) que não provocou qualquer modificação visualizável a vista desarmada, provocaram apenas a remoção da camada de resina tornando suas superfícies muito mais foscas.

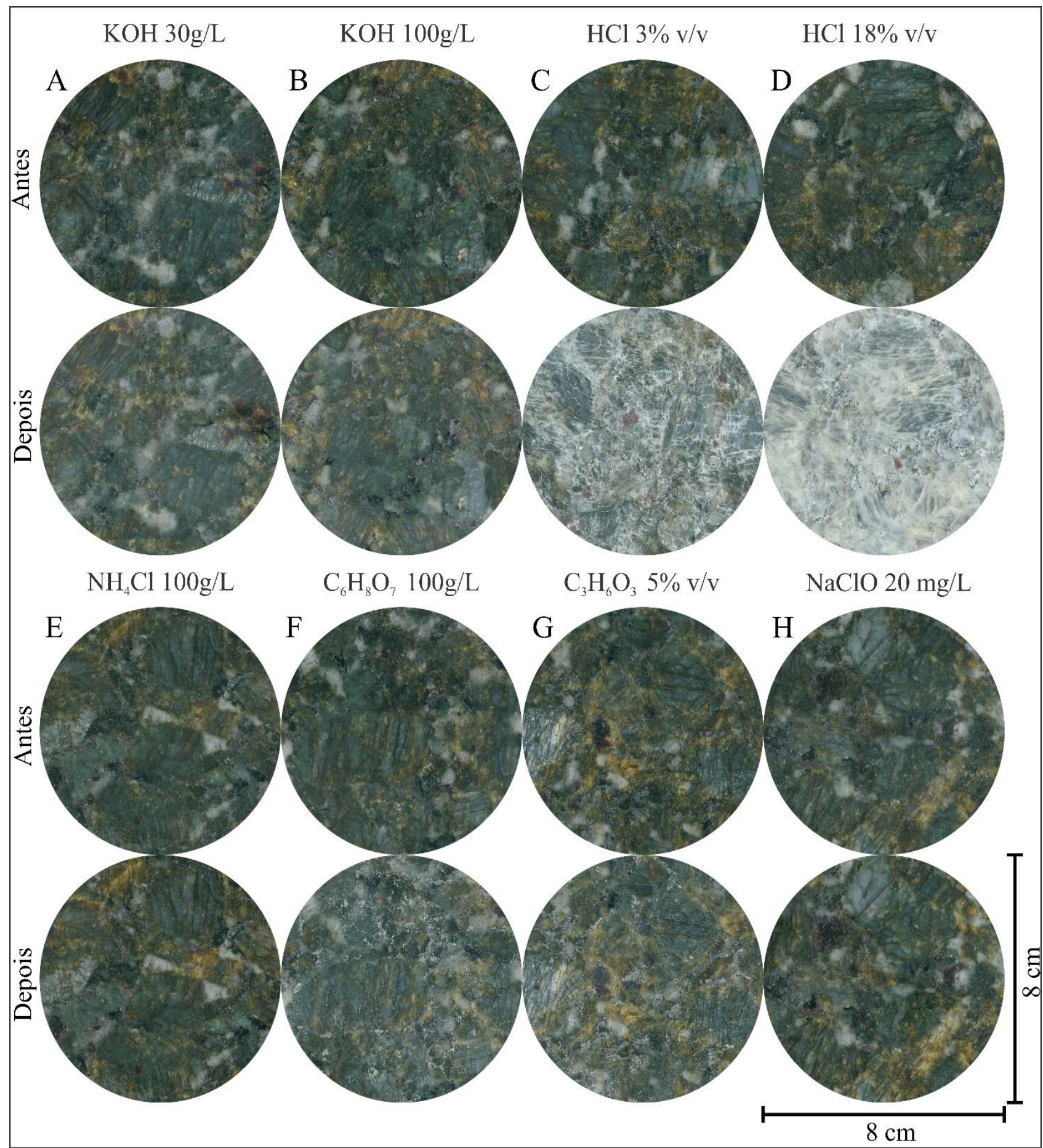

Figura 11 - Corpos de prova do Butterfly Green submetidos ao ensaio de ataque químico.

Legenda: $\mathrm{KOH}$ (Hidróxido de potássio); $\mathrm{HCl}$ (Ácido clorídrico); $\mathrm{NH}_{4} \mathrm{Cl}$ (Cloreto de amônio); $\mathrm{C}_{6} \mathrm{H}_{8} \mathrm{O}_{7}$ (Ácido cítrico); $\mathrm{C}_{3} \mathrm{H}_{6} \mathrm{O}_{3}$ (Ácido lático); $\mathrm{NaClO}$ (Hipoclorito de sódio).

\section{CONCLUSÕES}

As rochas ornamentais estudadas, na mina onde foram coletadas, estão distribuídas de forma caótica com contatos gradacionais, o que dificulta o planejamento das atividades na 
lavra. As variedades são representadas por quartzo sienitos com hiperstênio que se diferenciam, pela coloração, pelo grau de microfissuramento (Green apresentando o maior grau), pela presença de pertitas (Butterfly Beige) e, por consequência, pelos valores dos resultados dos ensaios físico-mecânicos.

A caracterização tecnológica mostra que as rochas apresentam grande similaridade composicional, textural e estrutural com resultados que estão bem próximos daqueles sugeridos como limítrofes para rochas graníticas pela NBR 15844 (ABNT, 2010b) com exceção do desgaste abrasivo Amsler e do módulo de ruptura que indicam que cuidados devem ser tomados no tocante a utilização dos litotipos em ambientes de alto tráfego, em fachadas com o uso de insertos metálicos e em pisos elevados. Em contrapartida os demais ensaios mostram que estas rochas apresentam índices físicos de porosidade e absorção d'agua que refletem segurança para suas aplicações em ambientes úmidos como banheiros e pias levando em consideração, no caso das aplicações em cozinhas, os resultados do ataque químico para manutenção e limpeza. Deixa-se claro que estas considerações são parciais e não são definitivas, sendo necessária uma série de outros ensaios para a especificação adequada das rochas.
$\mathrm{O}$ ensaio de ataque químico mostrou, tanto para o Butterfly Beige quanto para o Butterfly Green, que produtos feitos à base de ácido clorídrico como o ácido muriático não devem ser utilizados para sua limpeza devido aos danos causados pelo ácido clorídrico às rochas estudadas.

No Butterfly Green, o ácido clorídrico após remover a resina e lixiviar o hidróxido ferroso alojado nas microfissuras mostrou que, na realidade, o microclínio desta variedade é incolor e a coloração verde característica da rocha, contrariando ao que se encontra na literatura, se deve ao hidróxido ferroso que é verde. A causa do amarelamento dessa rocha é a oxirredução do hidróxido ferroso (verde) para hidróxido férrico (amarelo - avermelhado).

$\mathrm{O}$ reagente que provocou a maior perda de brilho foi o $\mathrm{C}_{6} \mathrm{H}_{8} \mathrm{O}_{7} 100 \mathrm{~g} / \mathrm{L}$, que a exemplo dos demais reagentes, com exceção do $\mathrm{NH}_{4} \mathrm{Cl}$ $100 \mathrm{~g} / \mathrm{L}$, removeu a camada de resina e deu um aspecto fosco às superfícies das amostras atacadas do Butterfly Green. Já no Butterfly Beige estas remoções de resina são menos perceptíveis devido ao tom claro deste litotipo. Entretanto, por estar presente nos sucos de frutas cítricas, recomenda-se cuidado ao manusear estas bebidas e/ou até as próprias frutas sobre estes materiais sob o risco de causar perdas localizadas de brilho.

\section{AGRADECIMENTOS}

À Guidoni Mineração Ltda pelo auxílio e cessão das amostras, à CAPES proc.: 3030/13-0, ao CNPq proc.: 141706/2012-0, ao DPM/UNESP e CETEM-ES.

\section{REFERÊNCIAS}

AIRES-BARROS, L.; MAURÍCIO, A.M.; FIGUEIREDO, C.A. Definição de um índice de alterabilidade de rochas por aplicação de métodos de análise de imagem baseados na morfologia matemática binária. Geociências, Revista Universidade de Aveiro, v. 5, fasc. 1/2, p. 95-102, 1991.

ALKIMIN, F.F.; PEDROSA-SOARES, A.C.; NOCE, C.M.; CRUZ, S.C.P. Sobre a evolução tectônica do Orógeno Araçuaí-Congo Ocidental. Geonomos, v. 15, n. 1, p. 24-43, 2007.

ABNT - ASSOCIAÇÃO BRASILEIRA DE NORMAS TÉCNICAS. NBR 12042: Materiais inorgânicos. Determinação do desgaste por abrasão. Rio de Janeiro, 3p., 1992.

ABNT - ASSOCIAÇÃO BRASILEIRA DE NORMAS TÉCNICAS. NBR 12766: (Anexo B) Rochas para revestimento - Determinação da Massa Especifica Aparente, Porosidade Aparente e Absorção de água Aparente. Rio de Janeiro, 2 p., 1992a.

ABNT - ASSOCIAÇÃO BRASILEIRA DE NORMAS TÉCNICAS. NBR 12767: (Anexo E) Rochas para revestimento. Determinação da resistência à compressão uniaxial. Rio de Janeiro, 2 p., 1992 c.
ABNT - ASSOCIAÇÃO BRASILEIRA DE NORMAS TÉCNICAS. NBR 12763: Rochas Para Revestimento. Determinação da resistência à flexão. Rio de Janeiro, 3 p., 1992d.

ABNT - ASSOCIAÇÃO BRASILEIRA DE NORMAS TÉCNICAS. NBR 12042: Materiais inorgânicos. Determinação do desgaste por abrasão, 3. Rio de Janeiro, p., 1992e

ABNT - ASSOCIAÇÃO BRASILEIRA DE NORMAS TÉCNICAS. NBR 12756: Rochas para Revestimento. Coeficiente de dilatação térmica linear. Rio de Janeiro, 3p., $1992 f$.

ASSOCIAÇÃO BRASILEIRA DE NORMAS TÉCNICAS (ABNT). NBR 13818: (Anexo - H) Determinação da resistência ao ataque químico. Rio de Janeiro, 1997.

ABNT - ASSOCIAÇÃO BRASILEIRA DE NORMAS TÉCNICAS. NBR 13818: (Anexo H) Placas cerâmicas para revestimento - Especificação e métodos de ensaio: Determinação da resistência ao ataque químico. Rio de Janeiro, 1997.

ABNT - ASSOCIAÇÃO BRASILEIRA DE NORMAS TÉCNICAS. NBR 15845: (Anexo A). Rochas para 
revestimento (normativo): análise petrográfica. Rio de Janeiro, p. 3-5, 2010a.

ABNT - ASSOCIAÇÃO BRASILEIRA DE NORMAS TÉCNICAS (ABNT). NBR 15845: (Anexo B) Rochas para revestimento. Métodos para ensaio. Determinação da Massa Especifica Aparente, Porosidade Aparente e Absorção de água Aparente. Rio de Janeiro, 2010. 3p.

ASSOCIAÇÃO BRASILEIRA DE NORMAS TÉCNICAS (ABNT). NBR 15845: (Anexo E) Rochas para revestimento - Métodos para ensaio. Resistência à Compressão Uniaxial. Rio de Janeiro, 3p., 2010.

ABNT - ASSOCIAÇÃO BRASILEIRA DE NORMAS TÉCNICAS. NBR 15844: Rochas para revestimento Requisitos para granitos. Rio de Janeiro, 6p., $2010 \mathrm{~b}$.

ABNT - ASSOCIAÇÃO BRASILEIRA DE NORMAS TÉCNICAS (ABNT). NBR 15845: (Anexo G) Rochas para revestimento - Métodos para ensaio- Flexão por carregamento em quatro pontos. Rio de Janeiro, 2010. 4p.

ABNT - ASSOCIAÇÃO BRASILEIRA DE NORMAS TÉCNICAS. NBR 15845: (Anexo H) Resistência ao impacto de corpo duro - Método de ensaio. Rio de Janeiro, 3 p., $2010 \mathrm{c}$.

ABNT - ASSOCIAÇÃO BRASILEIRA DE NORMAS TÉCNICAS (ABNT). NBR 15845: (Anexo F) Rochas para revestimento - Métodos para ensaio- Módulo de ruptura (flexão por carregamento em três pontos). Rio de Janeiro, 4p. 2010.

ABNT - ASSOCIAÇÃO BRASILEIRA DE NORMAS TÉCNICAS (ABNT). NBR 15845: (Anexo D) Rochas para revestimento - Métodos para ensaio- Resistência ao Congelamento e degelo. Rio de Janeiro, 4p., 2010.

BOLONINI, T. M. Geologia e Potencialidade do Granito "Vermelho Capão Bonito" (Sudoeste do Estado de São Paulo) como Rocha Ornamental. Rio Claro, 2011, 183 p. Dissertação (Mestrado em Geologia Regional). Instituto de Geociências e Ciências Exatas-Universidade Estadual Paulista.

BOLONINI, T.M. Estudo das Aplicações das Variedades de Um Quartzo Sienito Com Hiperstênio, Como Rochas Ornamentais, Com Auxílio da Caracterização Tecnológica e das Análises de Cor e Imagem. Rio Claro, 2015, 134 p. Tese de (Doutorado). Instituto de Geociências e Ciências Exatas-Universidade Estadual Paulista.

BOLONINI, T. M.; GODOY, A. M.; SAAR, L. C. A. Geologia e litogeoquímica das rochas graníticas do maciço Capão Bonito e o contexto geológico da sequência vulcanosedimentar Açungui. São Paulo, UNESP, Geociências, v. 32, n.3, p.452-470, 2013

BOLONINI, T.M.; GODOY, A.M.; BOLONINI, L.C.A.S.; SILVEIRA, L.L.L.; SANTOS, E. Análise de cor em imagens digitais e análise de brilho para rochas ornamentais submetidas ao ataque químico. In: SIMPÓSIO DE ROCHAS ORNAMENTAIS DO NORDESTE IX. Anais... João Pessoa: CETEM. 2016a.

BOLONINI, T.M.; GODOY, A.M.; BOLONINI, L.C.A.S.; SILVEIRA, L.L.L.; SANTOS, E. Quantificação mineralógica modal macroscópica, em rochas ornamentais submetidas à coloração seletiva por ataque químico, através da classificação supervisionada de imagens. In: SIMPÓSIO DE ROCHAS ORNAMENTAIS DO NORDESTE IX. Anais... João Pessoa: CETEM. 2016b.

BOLONINI, T.M.; GODOY, A.M.; BOLONINI, L.C.A.S.; SILVEIRA, L.L.L.; SANTOS, E. Uso da correlação entre imagens na classificação da descaracterização superficial de rochas ornamentais submetidas ao ataque químico. In: SIMPÓSIO DE ROCHAS ORNAMENTAIS DO NORDESTE IX. Anais... João Pessoa: CETEM, 2016c.

CAMARGO, J. L.; ARTUR, A. C.; SILVEIRA, L. L. L. Utilização de ensaios tecnológicos como auxílio na interpretação do polimento de rochas ornamentais. São Paulo, UNESP, Geociências, v. 34, n. 4, p.919-937, 2015.
CENTROROCHAS. Informativo das exportações de rochas agosto de 2016. Disponível em: http://www.centrorochas. org.br/. Acesso em: 25 de setembro de 2016

CPRM - SERVIÇO GEOLÓGICO DO BRASIL. Geologia da Folha de Mantena - SE.24-Y-A-VI. Programa Geologia do Brasil - mapa geológico da folha Mantena. Escala 1:100.000. Brasília, 2007a

CPRM - SERVIÇO GEOLÓGICO DO BRASIL. Geologia da Folha de Mantena - SE.24-Y-A-VI - Programa Geologia do Brasil - nota explicativa da folha Mantena. Escala 1:100.000. Brasília, 2007b.

FRASCÁ, M.H.B.O. Caracterização tecnológica de rochas ornamentais e de revestimento: estudo por meio de ensaios e análises das patologias associadas ao uso. In: SEMINÁRIO DE ROCHAS ORNAMENTAIS DO NORDESTE, 3, Recife. Anais ... Recife: Curso para Arquitetos e Engenheiros. 2002.

FRAZÃO, E. B. \& FARJALLAT, J.E.S. Características tecnológicas das principais rochas silicáticas brasileiras usadas como pedras de revestimento. In: CONGRESSO INTERNACIONAL DA PEDRA NATURAL I. Anais... Lisboa. p. 47-58, 1995

FRAZÃO, E. B. Tecnologia de Rochas na Construção Civil. São Paulo. ABGE, 132p. 2002.

FRAZÃO, E.B. \& FARJALLAT, J.E.S. Proposta de especificação para rochas silicáticas de revestimento. In: CONGRESSO BRASILEIRO DE GEOLOGIA DE ENGENHARIA, 8, 1996, Rio de Janeiro. Anais... Rio de Janeiro: ABGE. v.1, p. 369-380. 1996.

MARSHAK, S.; ALKIMI, F.F.; WHITTINGTON, A.; PEDROSA-SOARES, A.C. Extensional collapse in the Neoproterozoic Araçuaí orogen, eastern Brazil: a setting for reactivation of asymmetric crenulation cleavage. Journal of Structural Geology, v. 28, p. 129-147, 2006.

MARTINS, V.T.S.; TEIXEIRA, W.; NOCE, C.M.; PEDROSASOARES, A.C. Sr and Nd Characteristics of Brasiliano/PanAfrican Granitoid Plutons of the Araçuaí Orogen, Southeastern Brazil: Tectonic Implications. Godwana Research, v. 7, n. 1, p. 75-89, 2004.

NOCE, C.M.; PEDROSA-SOARES, A.C.; SILVA, L.C. DA; ARMSTRONG, R.; PIUZANA, D. Evolution of polycyclic basement complexes in the Araçuaí Orogen, based on U-Pb SHRIMP data: Implications for Brazil- Africa links in Paleoproterozoic time. Precambrian Research, v. 159, p. 60-78, 2007.

PAZZETO, A.A. Correlação entre propriedades petrográfica e comportamento tecnológico e de alterabilidade das rochas ornamentais silicáticas Diamante Negro (BA), Ocre Itabira e Branco Galaxy (ES). Rio Claro, 2011,189 p. Dissertação (Mestrado em Geologia Regional). Instituto de Geociências e Ciências Exatas - Universidade Estadual Paulista.

PEDROSA-SOARES, A.C.; NOCE, C.M.; VIDAL, P.H.; MONTEIRO, R.L.B.P.; LEONARDOS, O.H. Toward a new tectonic model for the Late Proterozoic Araçuaí (SE Brazil) West Congolian (SW Africa) Belt. Journal of South American Earth Science, v. 6, n. 1/2, p. 33-47, 1992.

PEDROSA-SOARES, A.C.; NOCE, C.M.; WIEDEMANN, C.M.; PINTO, C.P. The Araçuaí-West-Congo Orogen in Brazil: an overview of a confined orogen formed during Gondwanaland assembly. Precambrian Research, v. 110, p. 307-323, 2001.

PEDROSA-SOARES, A.C.; CASTAÑEDA, C.; QUEIROGA, C.; GRADIM, C.; BELÉM, J.; RONCATO, J.; NOVO, T.; DIAS, P.; GRADIM, D.; MEDEIROS, S.; JACOBSOHN, T.; BABINSKI, M.; VIEIRA, V. Magmatismo e tectônica do Orógeno Araçuaí no extremo Leste de Minas e Norte do Espírito Santo $\left(18^{\circ}-19^{\circ} \mathrm{S}, 41^{\circ}-40^{\circ} 30^{\prime} \mathrm{W}\right)$. Geonomos, v. 14, n. 1, 2, p. 97-111, 2006.

PEDROSA-SOARES, A.C.; NOCE, C.M.; ALKIMIM, F F.; SILVA, L.C.; BABINSKI, M.; CORDANI, U.; 
CASTAÑEDA, C. Orógeno Araçuaí: Síntese do Conhecimento 30 anos após Almeida. 1977. Geonomos, v. 15, n. 1, p. 1-16, 2007.

RONCATO JÚNIOR, J.G. As Suítes Graníticas Tipo-S do norte do Espírito Santo na região das Folhas Ecoporanga, Mantena e Nova Venécia. Belo Horizonte, 2009. Dissertação (Mestrado em Geologia). Universidade Federal de Minas Gerais, Instituto de Geociências.

SAAR, L.C.A. Avaliação dos "Granitos" Giallo São Francisco Real, Branco Dallas e Branco Marfim, do município de Barra de São Francisco/ES para aplicação como rocha ornamental e de revestimento. Rio Claro, 2013, 188 p. Dissertação (Mestrado em Geologia Regional). Instituto de Geociências e Ciências Exatas - Universidade Estadual Paulista.
SAAR, L. C. A.; GODOY, A. M.; BOLONINI, T. M. Considerações sobre os granitos Giallo São Francisco Real, Branco Dallas e Branco Marfim, no município de Barra de São Francisco - ES para aplicação como rocha ornamental e de revestimento. São Paulo, UNESP, Geociências, v. 34, n. 1, p.1-18, 2015.

VIDAL, F.W.H.; BESSA, M.F.; LIMA, M.A.B. Avaliação das rochas ornamentais do Ceará através de suas características tecnológicas. Série Tecnologia Minera, 74. Rio de Janeiro: CETEM/MCT, 30 p., 1999.

Submetido em 16 de setembro de 2015 Aceito em 02 de fevereiro de 2017 